\title{
Clinical picture of the amyloid arthropathy in patients with chronic renal failure maintained on haemodialysis using cellulose membranes
}

\author{
J MUÑOZ-GÓMEZ, ' R GÓMEZ-PÉREZ,' E LLOPART-BUISÁN.' \\ AND M SOLÉ-ARQUÉS ${ }^{2}$ \\ From the Departments of ${ }^{l}$ Rheumatology and ${ }^{2}$ Pathology, Hospital Clínico y Provincial, Barcelona, Spain
}

SUMmaRY The clinical picture of 15 patients ( 10 male, five female) with amyloid arthropathy secondary to chronic renal failure treated with haemodialysis has been studied. The average period of haemodialysis was $10 \cdot 8$ years. Joint symptoms appeared between three and 13 years after starting haemodialysis. No patient had renal amyloidosis. Early symptoms were varied and often overlapped: knee swelling (seven patients), painful and stiff shoulders (seven), and carpal tunnel syndrome (six) were the most prominent. Follow up showed extension to other joints. Joint effusions were generally of the non-inflammatory type. Radiologically, geodes and erosions of variable sizes were seen in the affected joints, which can develop into a destructive arthropathy. Amyloid was found in abdominal fat in three of the 12 patients on whom a needle aspiration was performed. Four of 12 patients showed changes compatible with amyloid infiltration in the echocardiogram. One patient had amyloid in the gastric muscular layer, another in the colon mucus, and two of four in rectal biopsy specimens. Amyloid deposits showed the presence of $\beta_{2}$ microglobulin in 10 patients. The clinical and radiological picture was similar to the amyloid arthropathy associated with multiple myeloma. These patients can develop systemic amyloidosis.

Key words: $\beta_{2}$ microglobulin, systemic amyloidosis.

The range of joint disease $\mathrm{e}^{1-3}$ in patients with chronic renal failure treated with periodic haemodialysis $(\mathrm{CRFH})$ has recently been increased by the description of new clinical entities which include a destructive spondyloarthropathy ${ }^{+7}$ and an erosive arthropathy,,$^{8-10}$ both of unknown origin. In 1985 we reported the presence of an amyloid type of arthropathy in such patients. ${ }^{11}$ This has also been described by other authors after fractures of the femoral neck, ${ }^{12-14}$ destructive hip arthropathy in two patients needing surgery, ${ }^{15}$ and in one patient with ankle synovitis. ${ }^{9}$ In our initial study we found a high percentage of patients had amyloid in the joint effusions as well as in the synovial membrane. Owing to the sensitivity and reproducibility of amyloid measurement we concluded that the finding

Accepted for publication 24 March 1987.

Correspondence to Dr J Muñoz-Gómez, Servicio de Reumatología. Hospital Clínico y Provincial, C/ Villarrocl 170. (08()36 Barcelona. Spain. of amyloid in joint fluid was sufficient evidence for the diagnosis of synovial amyloidosis. ${ }^{16}$

A group of patients with CRFH and proved amyloidosis (in synovial tissue or synovial fluid) has been studied in order to evaluate their clinical and radiological features.

\section{Patients and methods}

A group of 15 patients (Table 1) with CRFH and persistent swelling in one or several joints in whom synovial amyloidosis was confirmed by means of synovial biopsy (eight patients) and synovial fluid examination (seven patients) has been reviewed. The aetiology for their chronic renal failure was: glomerulonephritis (three patients), backflow hydronephrosis (one), nephroangiosclerosis (one), chronic nephritis (two), polycystic disease (four), and unknown (four). No patient had renal amyloidosis. Haemodialysis was performed by means of an artificial kidney with automatic supply. continuous 
Table 1 Clinical characteristics

\begin{tabular}{|c|c|c|c|c|c|c|}
\hline $\begin{array}{l}\text { Patient } \\
\text { No }\end{array}$ & $\begin{array}{l}\text { Age } \\
\text { (years) }\end{array}$ & Sex & $\begin{array}{l}\text { Dialysis } \\
\text { (years) }\end{array}$ & $\begin{array}{l}\text { Arthritis onset } \\
\text { after dialysis } \\
\text { lyears) }\end{array}$ & $\begin{array}{l}\text { Evolution of articular } \\
\text { symptoms (years) }\end{array}$ & $\begin{array}{l}\text { Actiology for } \\
\text { their CRI }\end{array}$ \\
\hline 1 & 61 & $M$ & 11 & 7 & $t$ & Glomerulonephritis \\
\hline 2 & 50 & $\mathrm{M}$ & 12 & 7 & 5 & Glomerulonephritis \\
\hline 3 & 49 & $M$ & 7 & 4 & 3 & Backflow hydronephrosis \\
\hline 4 & 56 & $\mathrm{M}$ & 10 & 6 & 4 & Nephroangiosclerosis \\
\hline 5 & 64 & $\mathrm{~F}$ & 11 & $s$ & 3 & Unknown \\
\hline 6 & 35 & $\mathrm{~F}$ & 16 & 13 & 3 & Chronic nephritis \\
\hline 7 & 57 & $\mathrm{~F}$ & 10 & 7 & 3 & Unknown \\
\hline 8 & 69 & $\mathrm{~F}$ & 10 & 0 & 4 & Polycystic discasc \\
\hline 9 & 65 & $\mathrm{M}$ & 10 & 5 & 5 & Unknown \\
\hline 10 & 61 & $\mathrm{M}$ & 12 & 6 & 6 & Polycystic discase \\
\hline 11 & 50 & M & 13 & 8 & 5 & Glomerulonephritis \\
\hline 12 & $6(1)$ & $\mathrm{M}$ & y) & 3 & 6 & Polveystic discase \\
\hline 13 & 65 & $\mathbf{M}$ & 1.3 & 9) & 4 & Chronic nephritis \\
\hline 14 & 67 & $\mathrm{M}$ & 111 & 8 & 2 & Unknown \\
\hline 15 & 59 & $\mathrm{~F}$ & 8 & 6 & 2 & Polycystic discatse \\
\hline
\end{tabular}

flow, and without capillary re-use. Cuprophane membranes were used.

The follow up time was $3 \cdot 3$ years (range $0 \cdot 5-6$ ) from the time the patient was first seen and 1.5 years (range $0 \cdot 15-2 \cdot 5$ ) from the time the diagnosis was made. Patients were seen every three to four months from the time of the first visit.

A detailed clinical history was taken of all the patients, and they underwent a full clinical and radiological examination with special emphasis on the locomotor system. An echocardiographic examination was performed in most patients. Their joint fluid was examined on various occasions (leucocyte count, search for crystals by regular and compensated polarised light microscopy both in fresh synovial fluid and after alizarin red staining). Amyloid was sought in joint fluid from all cases, in synovial tissue biopsy specimens from eight patients. in the abdominal fat of 12 patients, and in the ligament or carpal tunnel structures, or both, in 12 patients with carpal tunnel syndrome who had undergone surgery (bilateral in eight patients).

Synovial samples were fixed in $10 \%$ formol, and synovial fluid sediments (after centrifugation) were embedded in paraffin, stained with Congo red, and studied under polarising microscopy, seeking the green birefringence typical of amyloidosis. ${ }^{17}$ Most of the samples were treated with potassium permanganate by Wright's technique. ${ }^{\text {in }}$ In 10 patients we carried out a histochemical analysis with the avidinbiotin-peroxidase complex $(\mathrm{ABC})$ technique. After deparaffination and blockage of endogenous peroxidase and tissular biotin, sections were treated with rabbit antihuman $\beta_{2}$ microglobulin antibody $(\mathrm{DAKO})$ at $1 / 600$ dilution. The secondary antiserum used was biotin-swine antirabbit $\operatorname{IgG}$ (Vectastain) $\stackrel{\frac{c}{\oplus}}{\stackrel{5}{\rightarrow}}$ Thereafter sections were treated with the avidin- $\vec{c}$ biotin-peroxidase complex (Vectastain). Sections $\mathbb{O}^{-}$ from kidney, adrenal gland, and carpal tissues from patients with primary and secondary amyloidosiso and from the thyroid gland of a patient with known medullary carcinoma and amyloidosis were used as controls. Additional control tests were performed. replacing the primary antiserum by phosphate buffered serum.

\section{Results}

The 15 patients ( 10 male. five female), aged 35 to $69 \%$ years (mean 58), had undergone periodic haemo-⿳亠二口犬 dialysis for 7 to 16 years (mean 10.8). Jointo symptoms appeared between 3 and 13 years (mean 7) after haemodialysis started.

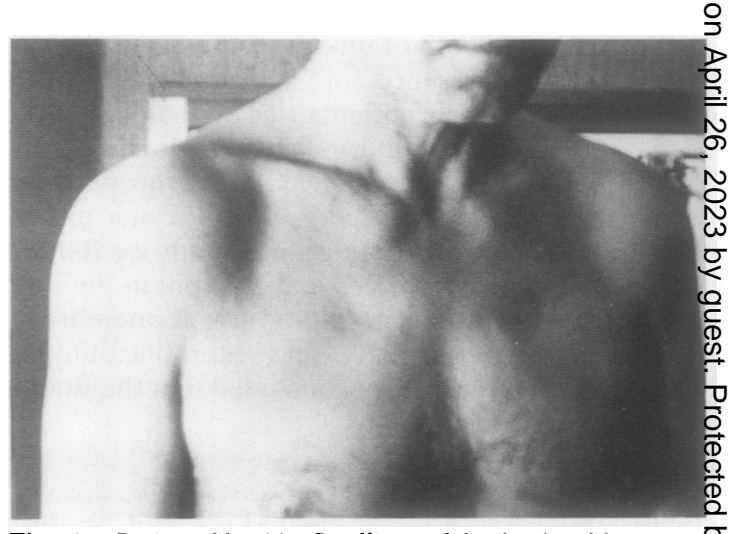

Fig. 1 Patient No 11. Swelling of both shoulders. 
Table 2 Early symptoms

\begin{tabular}{ll}
\hline Carpal tunnel syndrome & 2 \\
Carpal tunnel syndrome. knec & \\
$\quad$ pain or swelling. or both & 4 \\
Shoulder pain & 3 \\
Ankle and shoulder pain and & \\
$\quad$ knec swelling & 2 \\
Knee swelling & 1 \\
Ankle swelling & 1 \\
Shoulder swelling & 1 \\
Cervical and shoulder pain & 1 \\
\hline
\end{tabular}

CLINICAL MANIFESTATIONS (Fig. 1)

Early symptoms were varied and often overlapped. Knee swelling (seven patients), painful and stiff shoulders (seven patients), and carpal tunnel syndrome (six patients) were the most prominent (Table 2). The clinical articular picture had evolved over a two to six year period (mean four years), showing an extension to other joints during the follow up (Table 3).

The shoulders (14 patients), knees (13 patients), and the median nerve (13 patients) were the most frequently affected areas, often bilaterally. In patients with shoulder pain but without swelling there was always restricted mobility. Joint swelling was persistent in most of the patients, with total remission in certain joints in a few patients after several months of evolution. In general the symptoms were well tolerated, occurring with little or no pain and seemed to be caused by the capsular distension that accompanied significant effusions. One patient with chronic swelling of the shoulders, knees, and elbows suffered from occasional acute crisis requiring admission to hospital and synovial fluid culture to rule out the possibility of an infectious arthritis. The most troublesome symptoms affected the shoulders, whether or not swollen, and the sensory distribution area of the median nerve. Two patients of the series had a spontaneous femoral neck fracture, one with massive deposition of amyloid in synovial membrane and capsule.

Table 3 Clinical symptoms; end of follow up

\begin{tabular}{|c|c|c|c|c|}
\hline & Unilateral & Bilateral & Total & $\begin{array}{l}\text { Joints with } \\
\text { synovitis } \\
\text { arthralgia }\end{array}$ \\
\hline Shoulders & 3 & 11 & 14 & $12 / 13$ \\
\hline Knecs & 4 & 9 & 13 & $21 / 1$ \\
\hline Wrists & 5 & 2 & 7 & $9 /()$ \\
\hline Finger tenosynovitis & 3 & 4 & 7 & $11 / 0$ \\
\hline Ankles & & 5 & 5 & $8 / 2$ \\
\hline Hips & 1 & 3 & 4 & $(1 / 7$ \\
\hline Elbows & & 2 & 2 & $4 /()$ \\
\hline Carpal tunnel syndrome & 3 & 10 & 13 & \\
\hline
\end{tabular}

JOIN T FLUID

Cell counts varied from ()$\cdot 1 \times 10^{9} / 1$ to $9 \cdot 4 \times 10^{9} / 1$ (mean $\left.1.4 \times 10^{9} / 1\right)$, excluding the patient with acute crisis (mean $\left.32 \times 10^{\%} / 1\right)$. Crystals were not observed in any of the fluids, either in the unstained preparation or after alizarin red staining.

\section{RA DIOLOG Y}

The radiological changes included geodes of variable sizes and in some cases marked erosions (Figs 2 and 3, Table 4). Shoulder changes were the most frequent (17/24), showing in most of the cases a radiolucent defect of variable size (largest diameter 4-10 $\mathrm{mm}$ ), round or oval, and surrounded by a

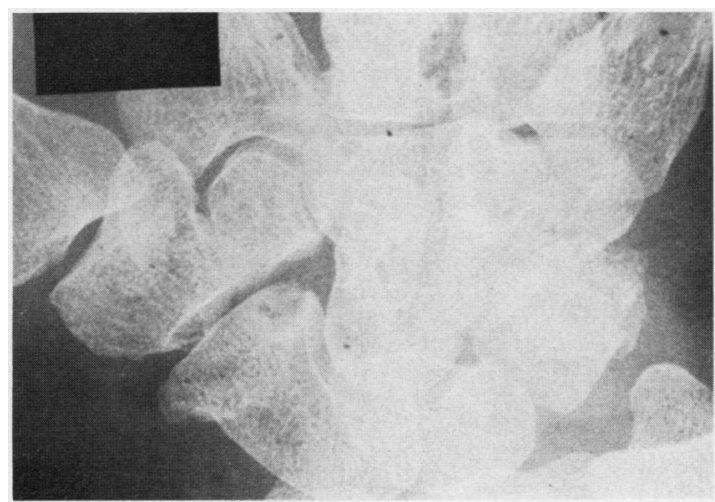

Fig. 2 Patient No 2. Cyst lesions in several carpal bones, especially in the proximal end of the third metacarpal, scaphoid, and capitate.

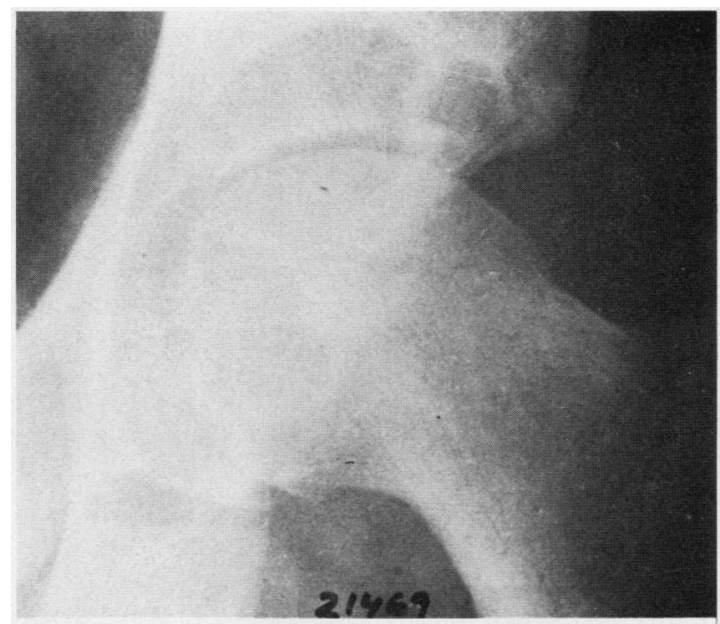

Fig. 3 Patient No 4. Cyst lesions in the right femoral head and acetabulum. 
sclerotic halo of variable thickness (Fig. 4). It was localised in the epiphyseal region between the anatomic and surgical necks. Normally there was only one radiolucent lesion present, two being observed in a few patients.

Bone erosion was very obvious in six shoulders (diameter larger than 5-13 mm), and in one case this was accompanied by similar lesions in the glenoid area.

Apart from the classical radiological picture of hyperparathyroidism or renal osteodystrophy, or both, present in some of our patients, alterations consistent with erosive spondyloarthropathy were found in four patients (No 7: L5-S1; No 9: C4-C5, C5-C6; No 11: C5-C6 (Fig. 5); No 13: C4-C5, C5-C6, D6-D7, D7-D8). The localisation of the amyloid deposits is shown in Table 5. Needle aspiration of abdominal fat was performed in 12 patients, being negative for amyloid in nine and positive in three patients. Four of 12 patients without cardiac symptoms showed changes com-

Table 4 Radiological changes

\begin{tabular}{llll}
\hline & Unilateral & Bilateral & $\begin{array}{l}\text { No of } \\
\text { patients } x \text { rayed }\end{array}$ \\
\hline Shoulders & 3 & 7 & 12 \\
Wrists & 4 & 5 & 14 \\
Fingers & 2 & 2 & 14 \\
Knees & 3 & 3 & 12 \\
Hips & 4 & 1 & 14 \\
Ankles & 1 & & 5 \\
Elbows & 1 & & 1 \\
\hline
\end{tabular}

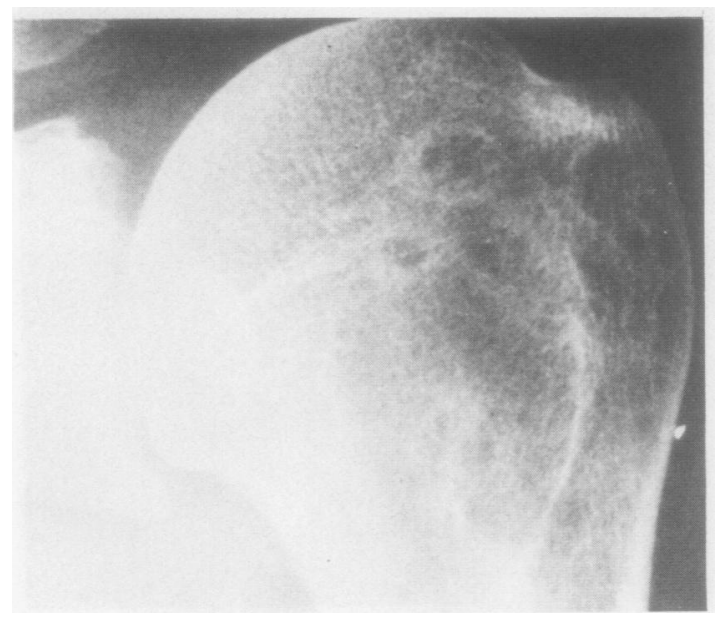

Fig. 4 Patient No 9. Oval and rounded radiolucent images surrounded by a sclerotic halo in left shoulder. patible with cardiac amyloid infiltration when studied by means of echocardiography. Immuno- $\vec{F}$ histochemical analysis proved the presence of $\beta_{2} \stackrel{\oplus}{\stackrel{\oplus}{+}}$ microglobulin in 10 patients: synovial fluid sediment (six patients), synovial membrane (five patients),

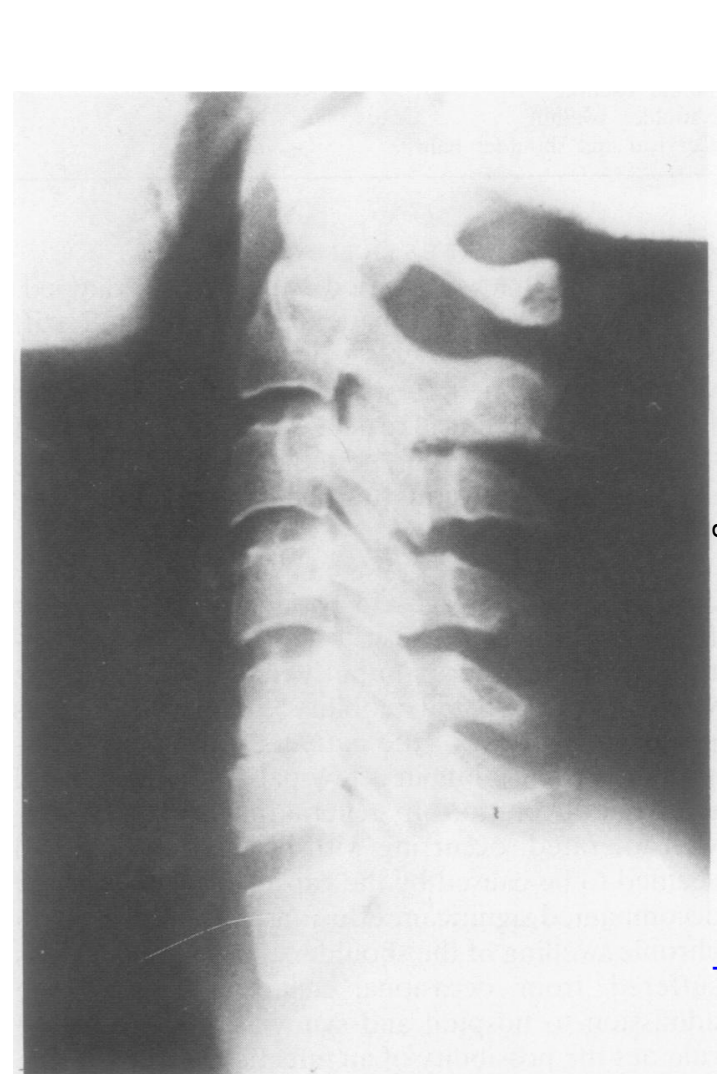

Fig. 5 Patient No 11. Erosive spondyloarthropathy at the C5-C6 level.

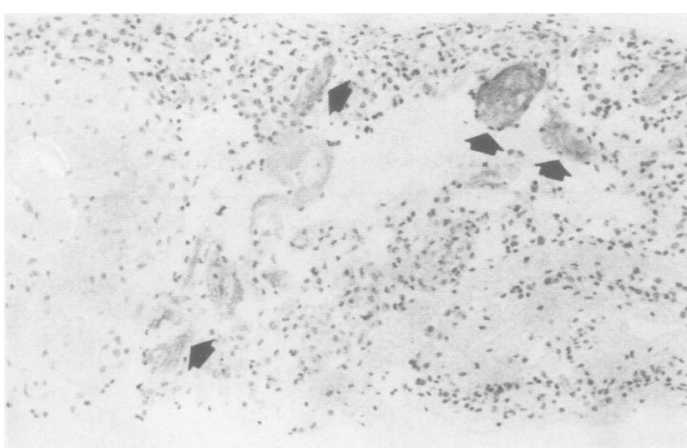

Fig. 6 Positive immunohistochemical reactions for $\beta_{2}$ microglobulin are arrowed. Synovial fluid sediment $(A B C)$. 
Table 5 Localisation of amyloid deposits

\begin{tabular}{|c|c|c|c|c|c|c|c|c|c|c|c|c|c|c|c|}
\hline & \multicolumn{15}{|c|}{ Patient No } \\
\hline & 1 & 2 & 3 & 4 & 5 & 6 & 7 & 8 & 9 & 10 & 11 & 12 & 13 & 14 & 15 \\
\hline Shoulder & SF & & & & & & $\mathrm{SF}$ & & & & SF & & $\mathrm{SF}$ & & \\
\hline Wrist & SF & & & & & & & & SF & & & SF & & SM & \\
\hline Knee & SF/SM & SF/SM & $\mathrm{SF} / \mathrm{SM}$ & SF/SM & SF/SM & SM & SF/SM & SF & & & & & & $\mathrm{SF}$ & SF \\
\hline $\begin{array}{l}\text { Ankle } \\
\text { Hip }\end{array}$ & & & & SM & & & & & SF & $\cdot$ & & & & & \\
\hline Carpal tunnel* & Bil. & Bil. & Bil. & Bil. & Bil. & & & - & Bil. & Uni. & Bil. & Uni. & Bil. & Uni. & \\
\hline Fat & - & - & - & - & - & + & - & - & - & & + & & - & + & \\
\hline Echot & - & - & - & - & - & & + & - & & + & - & & & - & + \\
\hline Other & RB- & RB + & & & RB + & & & & & & RB- & Colon & Gastric & & \\
\hline
\end{tabular}

${ }^{*}$ Amyloid positive in annular ligament, synovium, or perineural region.

$++=$ suggestive of amyloid infiltration.

$\mathrm{SF}=$ synovial fluid; $\mathrm{SM}=$ synovial membrane; $\mathrm{RB}=$ rectal biopsy specimen.

Table 6 Identification of $\beta_{2}$ microglobulin

\begin{tabular}{lll}
\hline Patient No & Synovial fluid & Synovial membrane \\
\hline 1 & + & \\
2 & + & + wrist \\
3 & + & + hip \\
4 & + & + knee \\
5 & + & + wrist \\
7 & + & \\
10 & + & + (gastric) \\
12 & & + wrist \\
13 & & \\
\hline
\end{tabular}

and gastric muscular layer (one patient) (Fig. 6, Table 6). None of the control sections stained for $\beta_{2}$ microglobulin.

\section{Discussion}

CLINICAL FEATURES

These 15 patients with CRF, after an average period of seven years of haemodialysis, developed a chronic arthropathy with joint pains or arthritis, or both, in few or many joints, mainly shoulders, knees, wrists, and fingers (tenosynovitis), though any joints could be affected, together with carpal tunnel syndrome (unilateral or bilateral) that tends to relapse, thus requiring further surgery. This has also been described by Brown et al. ${ }^{9}$ One of the most consistent clinical signs was persistent swelling of the knees or shoulders, or both. Joint effusions were generally of the non-inflammatory type, though some patients had acute crises with severe inflammatory effusions.

Radiologically, geodes and erosions of variable sizes were seen, which sometimes developed into a destructive arthropathy.

The clinical and radiological picture is very similar to the picture of amyloid arthropathy associated with multiple myeloma.

The clinical picture that has been described in several reports under diverse names: 'erosive azotemic osteoarthropathy', 'dialysis arthropathy', 'arthropathy of long term haemodialysis', ${ }^{10}$ "synovial amyloidosis ${ }^{15}$ is similar to that of our patients with proved amyloidosis. Although in some of these publications the presence of amyloidosis was not specifically looked for, it was present in the synovial membrane in one patient reported by Brown et al ${ }^{9}$ and in three by Bardin et $a l,{ }^{15}$ and in carpal tunnel structures in other series. ${ }^{10} 15$ The presence of erosions and geodes is a common feature in all these reports, and these cannot be ascribed to secondary hyperparathyroidism as some had these lesions with normal parathyroid hormone (PTH) levels, whereas others with lesions and abnormal PTH levels showed no improvement on returning to normal values. ${ }^{8101920}$ We therefore believe that in most of these patients amyloidosis plays an important part. ${ }^{13}$

'Destructive spondyloarthropathy' as described by Kuntz et $a l,{ }^{4}$ and attributed to the presence of apatite crystals after these had been found in one disc specimen, is probably part of the amyloid arthropathy of CRFH. In favour of this is the presence of amyloid. in the disc or intervertebral ligament, or both, in four patients described by Sebert et $a^{56}$ and the coincidence of destructive spondyloarthropathy in four of our 15 patients with amyloid arthropathy, in seven of 18 patients in Bardin's series, ${ }^{15}$ and in one of 15 patients reported by Chattopadhay et al. ${ }^{10}$

Erosions and geodes are probably due to amyloid bone invasion, ${ }^{12-15} 19$ presumably spreading from the synovium and could cause destructive arthritis in shoulders, knees, and hips, and pathological fractures of the hip, in particular the femoral neck $^{12142122}$ as seen in two of our patients. 
Our experience leads us to believe that the incidence of the different articular syndromes previously described in patients with $\mathrm{CRFH},{ }^{123}$ namely arthritis due to microcrystals (sodium urate, calcium pyrophosphate, apatite, and oxalates), infections, osteonecrosis, etc, is not very high. In a recent study of 102 patients with CRFH, 23 had renal osteodystrophy, five had periarticular calcifications, and in only one patient was an apatite associated knee arthritis' found, while the symptoms of 20 patients with joint pains, three patients with polyarthritis, and four with knee effusions remained unexplained. ${ }^{3}$ It is probable that some of these patients with partially unexplained symptoms might have been affected by synovial amyloidosis; if so, then the incidence of this condition may be very high.

\section{EXTENSION OF AMYLOIDOSIS}

In a previous study we mentioned the fact that CRFH amyloidosis did not show evidence of macroglossia, malabsorption syndrome, or cardiomyopathy, and abdominal fat aspiration was negative for amyloid in the six patients in whom it was sought. " This was confirmed by others in 30 patients with CRFH, 10 of whom also had a carpal tunnel syndrome. ${ }^{24}$ In the present series three of 12 patients showed amyloid in the fat aspirate.

Other authors have not been able to find amyloid in skin biopsy specimens (two patients) ${ }^{14}$ necropsy specimens (three patients) and a liver biopsy specimen (one patient), ${ }^{19}$ rectal biopsy specimens (two patients) ${ }_{15}^{15}$ rectal and skin biopsy specimens (three patients) ${ }^{25}$; all these patients, however, had amyloid in joints or the carpal tunnel. Nevertheless other reports indicate the possibility of systemic amyloidosis: positive rectal biopsy specimen in one patient, ${ }^{15}$ and clinical signs of systemic amyloidosis (macroglossia with positive Congo red biopsy specimen, heart failure, periorbital haematomas) in another patient. ${ }^{26}$ In our series we found large depositions of amyloid in the gastric muscularis layer in one patient undergoing gastrectomy for a neoplasm, in the colon mucus of a patient undergoing a hemicolectomy for diverticulosis, and in two of four patients undergoing rectal biopsies (Table 5). Another patient who had no articular symptoms and who is not included in this series showed the presence of amyloid in several organs (heart and prostate gland and in the subendothelium of arterioles and small arteries of the intestinal submucous membrane, heart, liver, lung, testicles, and adrenal glands) at necropsy.

The echocardiogram performed in 12 patients without cardiac symptoms showed changes compatible with amyloid infiltration in four.

In view of these observations we believe that patients with CRFH can develop systemic amyloido- sis, though in most the initial symptoms are confined $\frac{\mathrm{p}}{\mathrm{p}}$ to the joints.

AMYLOID CHARACTERISTICS

In all the patients in whom the staining characteristics were studied by means of Wright's test ${ }^{1 \mathrm{~s}}$ a $\overline{\bar{\omega}}$ congophilia resistant to potassium permanganate $\overrightarrow{\mathbb{D}}$ was shown, which suggests that this was not AA type amyloidosis, confirming our previous study. ${ }^{11}$ The same characteristic has been indicated by other $\overrightarrow{0}$ authors ${ }^{5} 152728$; in only two publications were the $\vec{\overrightarrow{ }}$ staining characteristics those of AA type amyloid. 1.314

Gejyo et al have shown that amyloid fibrils of $\mathrm{a}$ patient with CRF had as their major component a protein homologous with plasma $\beta_{2}$ microglobulin, ${ }^{29}{ }^{\circ}$ which would be consistent with our results when using the permanganate test. Moreover, it seems ${ }_{0}^{\omega}$ that both $\mathrm{AL}$ amyloid and $\beta_{2}$ microglobulin amyloid share the property of showing a congophilia resis- $\vec{D}$ tant to pretreatment with potassium permanganate and this may no longer be considered exclusively $\frac{C}{\infty}$ indicative of the presence of $\mathrm{AL}$ amyloid. ${ }^{16.34} \beta_{2}$ Microglobulin is known to accumulate in the blood- $-\infty$ stream of patients with CRF, ${ }^{31}$ and haemodialysis is. unable to remove it from the plasma. ${ }^{32} \beta_{2}$ Microglobulin levels in serum do not seem to be a usefuls marker for predicting the presence of amyloidosis in CRFH as no significant differences have been found between the values of $\beta_{2}$ microglobulin in a group of 191 patients with $\mathrm{CRFH}$ having no carpal tunnel $\overrightarrow{\vec{T}}$ syndrome and those of 10 patients with the syndrome. ${ }^{32}$ We believe, however, that the persistent and prolonged increase of $\beta_{2}$ microglobulin in these patients' serum is of great pathogenetic significance. Connors et al showed that large⿳⺈ amounts of intact $\beta_{2}$ microglobulin cause fibrillogenesis. ${ }^{30}$

Preliminary results obtained by immunohistoche-ô mical techniques ${ }^{16.33}$ from 10 of our patients con firm that the amyloid deposits contain $\beta_{2}$ microglo응 bulin, a fact also reported by other authors. ${ }^{622} 27$

DIALYSIS MEMBRANES

$\beta_{2}$ Microglobulin kinetics vary according to the types of membrane used. Patients undergoing dialysis using a cuprophane membrane show higher values than when using non-cellulose membranes (polysulphone, polyacrylonitrile). ${ }^{35-38}$ This increase was partly related to haemoconcentration, ${ }^{38}$ though thi has been refuted on the grounds that the increase occurs too early. ${ }^{39}$ It is significant that patients using non-cellulose membranes do not seem to show amyloid arthropathy ${ }^{21}$ and have a much lowe incidence of carpal tunnel syndrome. ${ }^{40}$

Given the possibility of amyloidosis occurring iब patients with CRFH, it would seem important to use 
a membrane that will ensure $\beta_{2}$ microglobulin excretion at as near to normal levels as possible (150 $\mathrm{mg} /$ day).

We would like to thank Dr A St J Dixon. Bath Institute for Rheumatic Diseases. Bath. England, for kindly reviewing the manuscript.

\section{References}

1 Massry S G, Bluestone R. Klinemberg J R, Coburn J W. Abnormalities of the musculoskeletal system in hemodialysis patients. Semin Arthritis Rheum 1974: 4: 321-49.

2 Kuntz D. Bardin T. Manifestations articulaires des hémodialysés. Encyclopédie Med Chirg Paris. Appareil locomoteur. 14276 A $^{111}, 9-1985$.

3 Chou Ch T. Wasserstein A. Schumacher H R Jr. Fernandez P. Musculoskeletal manifestations in hemodialysis patients. $J$ Rheumatol 1985: 12: 1149-53.

4 Kuntz D. Naveau B. Bardin T. Drueke T. Treves R, Drill A. Destructive spondylarthropathy in hemodialyzed patients. Arthritis Rheum 1984: 27: 369-75.

5 Sebert J L. Fardellone P. Maric A. et al. Destructive spondylarthropathy in hemodialyzed patients: possible role of amyloidosis. Arthritis Rheum 1986; 29: 301-3.

6 Sebert J L. Bardin T. Shirama T, Marie A. Fournier A. Kuntz D. Amyloidosis and beta 2-microglobulin in destructive spondylarthropathies of hemodialysis patients [Abstract]. Arthritis Rheum 1986; 29 (suppl): S49.

7 Muñoz-Gomez J. Estrada Laza P. Destructive spondylarthropathy in hemodialyzed patients. Arthritis Rheum 1986; 29: $1171-2$.

8 Rubin L A. Fam A G. Rubenstein J. Campbell J, Saiphoo C. Erosive azotemic osteoarthropathy. Arthritis Rheum 1984: 27: 1086-94.

9 Brown E A. Arnold I R. Gower P E. Dialysis arthropathy: complication of long term haemodialysis. $\mathrm{Br}$ Med J 1986: 292: 163-6.

10 Chattopadhay C. Ackrill P. Clague R B. Arthropathy of long term haemodialysis [Abstract]. Br J Rheumatol 1986; 25: 121.

11 Muñoz-Gómez J. Bergadá-Barado E. Gómez-Pérez R. et al. Amyloid arthropathy in patients undergoing periodical haemodialysis for chronic renal failure: a new complication Ann Rheum Dis 1985: 44: 729-33.

12 Huaux J P. Nöel H. Malghem J. Maldague B, Devogelaer J P. Nagant de Deuxchaisnes C. Amylose articulaire, fracture du col fémoral et hémodialyse périodique chronique. Rev Rhum Mal Osteoartic 1985: 52: 179-82.

13 Huaux J P. Nöel H. Malghem J. Maldague B. Devogelaer J P. Nagant de Deuxchaisnes C. Erosive azotemic osteoarthropathy: possible role of amyloidosis. Arthritis Rheum 1985; 28: 1075-6.

14 DiRaimondo C R. Casey T T. DiRaimondo Ch V. Stone W J. Pathologic fractures associated with idiopathic amyloidosis of bone in chronic hemodialysis patients. Nephron 1986; 43: 22-7.

15 Bardin T, Kuntz D. Zingraff J, Voisin M C. Zelmar A. Lansaman J. Synovial amyloidosis in patients undergoing long term hemodialysis. Arthritis Rheum 1985; 28: 1052-8.

16 Muñoz-Gómez J. Gómez-Pérez R. Solé-Arqués M. LlopartBuisán E. Synovial fluid examination for the diagnosis of synovial amyloidosis in patients with chronic renal failure undergoing hacmodialysis. Ann Rheum Dis 1987: 46: 324-6.

17 Cohen A S. The diagnosis of amyloidosis. In: Cohen A S, ed. Laboratory diagnostic procedures in the rheumatic diseases. Boston: Little. Brown, 1967: 332.

18 Wright J R. Calkins E. Humphrey R. Potassium permanganate reaction in amyloidosis. Lab lnvest 1976: 36: 274-81.

19 Fenves A Z. Emmett M. White M G. Greenway G. Michacls D B. Carpal tunnel syndrome with cystic bone lesions secondary to amyloidosis in chronic hemodialysis patients. Am J Kidney Dis 1986: 7: 130-4.
20 Bardin T, Kuntz D, Vernejoul M C, Lafforgue B, Zingraff J. Rheumatic syndromes after 10 years of hemodialysis [Abstract]. Arthritis Rheum 1986; 29 (suppl): S50.

21 Vanderbroucke J M, Jadoul M, Maldague B, et al. Possible role of dialysis membrane characteristics in amyloid osteoarthropathy. Lancet 1986; i: $1210-1$

22 Bardin T, Kuntz D, Nöel L H, et al. Amyloid deposits in hemodialysis patients react with beta 2 -microglobulin antibody [Abstract]. Arthritis Rheum 1986; 29 (suppl): S11.

23 Resnick D, Niwayama G. Parathyroid disorders and renal osteodystrophy. In: Resnick D, Niwayama G, eds. Diagnosis of bone and joint disorders. Philadelphia: Saunders, 1981: 180359.

24 Varga J, Felson D, Skinner M, Cohen A S. Absence of amyloid in fat aspirates of long term hemodialysis patients [Abstract]. Arthritis Rheum 1986; 29 (suppl): S14.

25 Clanet M. Mausat M. Durroux R, et al. Syndrome du canal carpien, ténosynovite amyloide et hémodialyse périodique. Rev Neurol (Paris) 1981; 137: 613-24.

26 Hervé J P. Clédes J, Bourbigot B, et al. Apparition d'une amylose généralisée au cours de l'hémodialyse. A propos d'une observation [Abstract]. Nephrologie 1984; 5: 92.

27 Skinner M, Shirama T. Connors L H, Cohen A S. Increased beta 2 -microglobulin may be the major cause of hemodialysis associated amyloidosis [Abstract]. Arthritis Rheum 1986; 29 (suppl): S9.

28 Allieu Y, Asencio C, Mailhe D. Baldet P. Mion C. Syndrome du canal carpien chez l'hémodialysé chronique. Approche étiopathogénique. Rev Chir Orthop 1983; 69: 233-8.

29 Gejyo F, Yamada T, Odani S, et al. A new form of amyloid protein associated with chronic hemodialysis was identified as beta 2-microglobulin. Biochem Biophys Res Commun 1985; 129: $701-6$.

30 Connors L H, Skinner M, Kagan H M, Shirama T, Cohen A S. Formation of fibrillar material from amyloid precursor proteins, prealbumin and beta 2-microglobulin [Abstract]. Arthritis Rheum 1986; 29 (suppl): S7.

31 Vincent C. Revillard J P, Galland M. Traegar J. Serum beta 2microglobulin in hemodialysed patients. Nephron 1978: 21: 260-8.

32 Gejyo F. Homma N. Suzuki Y. Arakawa M. Serum levels of beta 2-microglobulin as a new form of amyloid protein in patients undergoing long term hemodialysis. $N$ Engl $J$ Med 1986; 314: 585-6.

33 Muñoz-Gómez J, Solé-Arqués M. Amyloid arthropathy in haemodialysed patients. Ann Rheum Dis 1986; 45: 879-80.

34 McClure J, Bartley C J. Ackrill P. Carpal tunnel syndrome caused by amyloid containing $\beta_{2}$ microglobulin: a new amyloid and a complication of long term haemodialysis. Ann Rheum Dis 1986; 45: 1007-11.

35 Kostic S. Djordjević V. Leciî N. Stefanović V. Serum beta 2-microglobulin in patients on maintenance hemodialysis. The effect of dialysis membrane. Kidney Int 1985; 28: 338.

36 Hauglastaine D, Waer M. Michelsen P. Goebels J. Vandeputte M. Haemodialysis membranes, serum beta 2-microglobulin. and dialysis amyloidosis. Lancet 1986; i: 1211-2.

37 Ackrill P. Robinson E L. Hill K. McClure J C. Reduction in serum beta 2-microglobulin levels in long term haemodialysis patients and relief of shoulder pain. Proc Eur Dial Transplant Assoc Eur Ren Assoc 1986; 23: 106.

38 Bommer J, Seeling H P. Seeling R, Ritz E. Beta 2 microglobulin levels in hemodialysed patients. Proc Eur Dial Transplant Assoc Eur Ren Assoc 1986: 23: 111.

39 Vanderbroucke J M, van Ypersale de Strihou. Relationship between membrane characteristics and dialysis induced changes in beta 2-microglobulin levels. Proc Eur Dial Transplant Assoc Eur Ren Assoc 1986; 23: 156.

40 Chanard J. Lavaud S. Toupance O. Melin J P. Gillery P. Beta 2-microglobulin associated amyloidosis in chronic hacmodialysis patients. Lancet 1986; i: 1212. 